\title{
In vitro antioxidant and ex vivo anti- cataract activity of ethanolic extract of Cineraria maritima: a traditional plant from Nilgiri hills
}

Sumit Durgapal ${ }^{1,2^{*}}$ (D), Vijay Juyal ${ }^{1}$ and Anurag Verma ${ }^{2,3}$

\begin{abstract}
Background: Cineraria maritima has a long history of use in the treatment of cataract and other eye-related problems in the homeopathic system of medicines. High oxidative stress is one of the major underlying causes of cataract which results in the precipitation of natural protein present in the lenses with aging. This research has been carried out to determine the anti-cataract activity of $C$. maritima by performing various antioxidant techniques such as 1,1-diphenyl-2-picrylhydrazyl, nitric oxide, hydrogen peroxide, and studies in oxidative stress-induced ex vivo cataract model.

Results: Results of the study conducted in the ethanolic extract of aerial parts (leaves and stems) of C. maritima revealed the presence of various phytoconstituents such as alkaloids, phenols, flavonoids, etc. Total phenol and total flavonoid content was found to be $6.31 \pm 0.06 \% \mathrm{w} / \mathrm{w}$ and $2.14 \pm 0.09 \% \mathrm{w} / \mathrm{w}$ respectively, which revealed that the plant contains a good amount of these compounds and hence possesses good antioxidant activity.

Furthermore, $I_{50}$ values obtained from all the methods gave strong evidence regarding the antioxidant potential of this plant. Anti-cataract activity was also investigated using goat eye lenses and promising results were obtained which speak voluminously about its anti-cataract potential and support its well-prescribed use.

Conclusion: Results obtained with this study clearly supported the significant antioxidant potential and anticataract activity of this plant. Further, this plant demands great attention for the development of suitable novel dosage forms for the effective treatment of cataract.
\end{abstract}

Keywords: Cineraria maritima, Cataract, Antioxidant activity, DPPH, Nitric oxide

\section{Background}

Cataract, the leading cause of avoidable blindness is responsible for almost $50 \%$ of cases globally $[1,2]$. According to the recent report of the World Health Organization (WHO), this percentage will double in the coming two decades if suitable measures would not be taken effectively

\footnotetext{
* Correspondence: Sumit.1459@gmail.com

'Department of Pharmaceutical Sciences Bhimtal, Kumaun University Nainital, Nainital, Uttarakhand Pin Code 263136, India

${ }^{2}$ School of Pharmaceutical Sciences, IFTM University, Moradabad, Uttar

Pradesh Pin Code 244102, India

Full list of author information is available at the end of the article
}

in time $[3,4]$. Presently, surgery is the only treatment available which itself is associated with severe postoperative complications such as posterior capsule opacity, intraocular lens dislocation, inflammation of eyes, macular edema, endophthalmitis, and ocular hypertension $[5,6]$. Socioeconomic problems like illiteracy, poverty, inaccessibility, and overall cost of the treatment are other considerable major barriers to successful treatment [7]. Studies revealed that oxidative stress (OS) is one of the main underlying causes for the development of cataract $[8,9]$. Formation of reactive oxygen species (ROS) such as hydroxyl radicals, hydrogen peroxide, and superoxide anions 
due to inefficient defense systems and non-neutralizing action of natural antioxidant enzymes (glutathione, glutathione peroxidase, superoxide dismutase, and catalase) found in the normal crystalline lens is the main reason of the occurrence of OS. These antioxidant enzymes play a very significant role in the protection of lens proteins and lens fiber cell membranes [10,11]. Excessive increase in ROS results in the denaturation of lens proteins, nucleic acid, and lipids causing the development of cataract. Studies claimed a significant decrease in the activity of these natural antioxidants in the lens due to OS during cataract formation. Consequently, the development of plant-based pharmaceutical dosage form possessing remarkable antioxidant potential would be a boon to this global challenge. Successful prevention of ROS using plants seems a new hope on the horizon for giving a major breakthrough in preventing or at least delaying the onset of cataract with the least or no side effects [12]. Cineraria maritima $L$. (Syn. Senecio bicolor Wild) Tod, spp. Cineraria, (Syn. S. cineraria DC) has been used for the treatment of cataract and other severe eye-related conditions like conjunctivitis, opacity, and corneal clouding in the homeopathic system since time immemorial. It is an annual exotic medicinal shrub, which belongs to the Asteraceae family. It is native to the Mediterranean region, but in India, this exotic plant is cultivated by the Central Council for Research in Homeopathy in Nilgiri hills (at an altitude of $1990 \mathrm{~m}$ above sea level, $11^{\circ} 18^{\prime}-11^{\circ} 41^{\prime} \mathrm{N}$ Latitude and $76^{\circ} 37^{\prime}-76^{\circ} 49^{\prime} \mathrm{E}$ Longitude,), Tamil Nadu [13]. It is a perennial shrub with a height varying from 0.6 to $1.0 \mathrm{~m}$. It is white in color and woolly throughout, especially under the leaves. Leaves are pinnate with oblong and obtuse segments. Flowers are hermaphrodite and branching generally starts from the base. It is also cultivated as an ornamental plant and sometimes called dusty miller [14]. Experimental studies suggested the presence of potassium, calcium, aluminum, manganese, iron, and phosphorus in C.maritima [15]. Leaves of the plant collected in Egypt were found to possess various flavonoids such as quercetin, dihydroquercetin, quercetrin, apigenin 7-O-glucoside, and luteolin 7-Oglucoside and their oil contained $\alpha$-pinene (27.8\%), camphene $(22.9 \%)$, and borneol (7.4\%) as major constituents [16]. Other studies suggested the presence of different pyrrolizidine alkaloids and other compounds with hydrocarbons and caryophyllene oxide being the most abundant compounds $[14,17]$. Research studies showed that this plant possesses significant antioxidant potential which might be the possible reason for its anti-cataract effect [18]. This plant has been selected because we believe that in spite of its high anti-cataract potential, it is underrated and has not yet been explored from the novel drug delivery systems (NDDS) point of view. The development of drug delivery systems using plants demands the identification of compounds responsible for their activity. In our study, we have qualitatively and quantitatively identified the presence of a significant amount of phenols and flavonoids in the Indian species of C.maritima for the first time. Considerable effect of plant extract in the concentration of protein and ions such as sodium and potassium which are essential for the transparency of the lenses were also estimated. These studies may act as a stepping stone for the development of better delivery systems of this potential candidate as compared to its presently available eye drops. Anatomical and physiological barriers of the eye are the key aspects for the ineffectiveness of drops in achieving optimum bioavailability to obtain maximum therapeutic outcomes, thus restricting the potential of C.maritima. Therefore, an attempt was made to determine the antioxidant potential of C.maritima utilizing the principle of total phenolic and flavonoid content and different in vitro antioxidant techniques such as 1,1-diphenyl-2-picrylhydrazyl (DPPH), hydrogen peroxide, and nitric oxide. Further, to know the influence of this plant in lens protein and vital lens elements such as potassium and others, biochemical testing studies were done in goat eye lenses [18].

\section{Methods}

\section{Plant and chemical procurement}

The plant has been purchased from the Centre of Medicinal Plants Research in Homeopathy (Central Council for Research in Homeopathy), Nilgiri district, Tamil Nadu, India, in November 2019. The same has been identified and supplied as Senecio bicolor (Willd.) Tod, ssp. Cineraria synonyms: Cineraria bicolor Willd., Cineraria maritima L. belongs to the (Asteraceae). Certificate for the purchase and identification (F.No. 6-2/2019-20/CMPRH/Tech/212) of this plant has been issued by Dr. S. Rajan Officier Incharge Centre of Medicinal Plants Research in Homeopathy (Central Council for Research in Homeopathy) Emerald Tamil Nadu, India. Chemicals such as quercetin, rutin, gallic acid, and sodium selenite were purchased from Sigma-Aldrich Chemical Pvt. Ltd. Bangalore, India. DPPH was purchased from Hi-media Laboratories Pvt. Ltd. Mumbai, India. Ascorbic acid, hydrogen peroxide, and sulfanilamide were purchased from Loba Chemie, Mumbai, India. Methanol, sodium chloride, potassium chloride, and magnesium chloride were purchased from Merck Life Science Pvt. Ltd. Mumbai, India. Other chemicals and solvents were purchased from Central Drug House Pvt. Ltd., Mumbai, India, and S.D. Fine Chem. Ltd., Mumbai, India. A rotating vacuum evaporator (BUCHI, Switzerland) was utilized for the recuperation of solvents under decreased tension. UV/ VIS spectrophotometer (Schimadzu, Japan) was utilized for stepping through absorbance of exam tests.

\section{Preparation of plant extract}

For the preparation of plant extract, aerial parts (leaves and stems) of plants were shade dried and powdered 
carefully. Then, $10 \mathrm{~g}$ of the powdered material was weighed accurately and extracted with $200 \mathrm{ml}$ of $95 \%$ ethanol in a Soxhlet apparatus. The solvent was completely evaporated under reduced pressure at $50{ }^{\circ} \mathrm{C}$ and dried in vacuum. The material thus obtained was filtered and dried. Further, percentage yield was calculated $(11.52 \%)$ and this was used as an extract to carry out experimental studies [19].

\section{Phytochemical screening of plant extract}

Identification of various phytochemicals such as alkaloids, carbohydrates, flavonoids, glycosides, etc. was carried out as per their standard procedures [20-24].

\section{Total phenol content}

\section{Preparation of standard curve}

For the preparation of the standard curve, $20 \mathrm{mg}$ of accurately weighed gallic acid was carefully transferred into the 100-ml volumetric flask and dissolved in $20 \mathrm{ml}$ of $50 \% \mathrm{v} / \mathrm{v}$ methanol. Then, the final volume was made up to the $100-\mathrm{ml}$ mark with $50 \% \mathrm{v} / \mathrm{v}$ methanol to obtain a stock solution of $200 \mu \mathrm{g} / \mathrm{ml}$ concentration of gallic acid. Samples of different concentrations of gallic acid such as $20,40,60,80,100$, or $120 \mu \mathrm{g} / \mathrm{ml}$ were prepared by the proper dilution of stock solution. After this, $1 \mathrm{ml}$ of aliquot from each sample was taken in different test tubes and further diluted to $10 \mathrm{ml}$ with $50 \%$ methanol and $1.5 \mathrm{ml}$ Folin Ciocalteu's reagent was added to each test tube. All the test tubes were then incubated at room temperature for $5 \mathrm{~min}$ and $4 \mathrm{ml}$ of $20 \% \mathrm{w} / \mathrm{w}$ aqueous solution of sodium carbonate was added to each test tube and the final volume was adjusted up to the mark of 25 $\mathrm{ml}$ with $50 \% \mathrm{v} / \mathrm{v}$ methanol. Each test tube was agitated vigorously for the mixing of contents and left aside for $30 \mathrm{~min}$ at room temperature and then the absorbance of all the samples was measured at $765 \mathrm{~nm}$ by using a UV/ VIS spectrophotometer against $50 \% \mathrm{v} / \mathrm{v}$ methanol as a blank [25].

\section{Preparation of test samples}

Firstly, $50 \mathrm{mg}$ of extract was accurately weighed with the help of digital balance and extracted with $50 \%$ methanol $(3 \times 5 \mathrm{ml})$ by maceration for at least $2 \mathrm{~h}$. Then, filtration was done and volume was made up to $50 \mathrm{ml}$ with $50 \%$ methanol in a cleaned and dried volumetric flask. After this $1 \mathrm{ml}$ of aliquot was taken in a test tube and $1.5 \mathrm{ml}$ of Folin Ciocalteu's reagent was added to it and kept aside for $5 \mathrm{~min}$ for incubation to be carried out at room temperature. Then, $4 \mathrm{ml}$ of $20 \% \mathrm{w} / \mathrm{w}$ aqueous solution of sodium carbonate was added to the test tube and the final volume up to $10 \mathrm{ml}$ was made by using $50 \% \mathrm{v} / \mathrm{v}$ methanol. For the proper mixing of contents, the test tube was shaken vigorously and then left aside for $30 \mathrm{~min}$ for incubation at room temperature, and immediately after the incubation, absorbance was measured at $765 \mathrm{~nm}$ against the blank (50\% v/v methanol) with the help of the UV/VIS spectrophotometer.

\section{Quantification of total phenol content}

A standard curve for the estimation of total phenol content (TPC) was prepared by using gallic acid. Different concentrations of gallic acids such as $20,40,60,80,100$, and $120 \mu \mathrm{g} / \mathrm{ml}$ were made and absorbance for each concentration was estimated. Then a graph was plotted by taking the concentration on the $\mathrm{X}$-axis and absorbance on the $\mathrm{Y}$-axis to obtain the regression equation of the standard curve. From this equation of standard curve, gallic acid equivalents were determined and the result was expressed as percentage $\mathrm{w} / \mathrm{w}$ (mean \pm S.D). The percentage of total phenolic content in a sample of plant extract was determined by using the formula:

$$
\operatorname{TPC}(\% \mathrm{w} / \mathrm{w})=\mathrm{GAE} \times \mathrm{V} \times \mathrm{D} \times 10^{-6} \times 100 / \mathrm{W} .
$$

where $\mathrm{GAE}=$ gallic acid equivalents $(\mu \mathrm{g} / \mathrm{ml}) ; \mathrm{V}=$ total volume of sample $(\mathrm{ml}) ; \mathrm{D}=$ dilution factor; $\mathrm{W}=$ sample weight $(\mathrm{g})$.

\section{Total flavonoid content}

For the determination of total flavonoid content (TFC), the aluminum chloride complex assay method was used. In this method, quercetin was used as a standard and all the determinations were done by plotting the standard curve of quercetin [25].

\section{Preparation of standard curve of quercetin}

For the preparation of the standard curve of quercetin, firstly, a stock solution was prepared by dissolving accurately weighed $20 \mathrm{mg}$ of quercetin in $20 \mathrm{ml}$ of methanol in a $100-\mathrm{ml}$ volumetric flask and the final volume was made up to the mark by adding methanol to obtain a solution of $200 \mu \mathrm{g} / \mathrm{ml}$ concentration. Then, samples of various concentrations such as $30,60,90,120,150$, and $180 \mu \mathrm{g} / \mathrm{ml}$ with the stock solution of quercetin in methanol were prepared. Then, $0.5 \mathrm{ml}$ of aliquot was taken from each sample and $1.5 \mathrm{ml}$ of $95 \%$ methanol, $0.1 \mathrm{ml}$ of aluminum chloride (10\%), $0.1 \mathrm{ml}$ of $1 \mathrm{M}$ potassium acetate, and $2.8 \mathrm{ml}$ distilled water were added separately to each of the samples and incubated for $30 \mathrm{~min}$ at room temperature. After this, with the help of a UV/VIS spectrophotometer, the absorbance of various samples was determined at $415 \mathrm{~nm}$. For the preparation of the blank sample, the amount of aluminum chloride $(10 \%)$ was replaced with the same amount of distilled water in the abovementioned procedure. 


\section{Preparation of test samples}

Accurately weighed $50 \mathrm{mg}$ of extract was dissolved separately in $50 \mathrm{ml}$ of methanol. Similarly, $0.5 \mathrm{ml}$ of stock solution was reacted with aluminum chloride for the determination of flavonoids content as described in the above section. The amount of aluminum chloride (10\%) was substituted by the same amount of distilled water in the blank. The test sample was prepared by dissolving accurately weighed $50 \mathrm{mg}$ of plant extract in $50 \mathrm{ml}$ of methanol, and for the determination of flavonoids content, $0.5 \mathrm{ml}$ of stock solution was reacted with $10 \%$ aluminum chloride. For the preparation of the blank, aluminum chloride was replaced with distilled water.

\section{Quantification of total flavonoid content}

For the estimation of TFC, a standard curve of quercetin was plotted by taking the concentration of quercetin against absorbance. With the help of the regression equation of this curve, quercetin equivalents were calculated and the result was expressed as percentage $\mathrm{w} / \mathrm{w}$ (mean \pm S.D).

A standard curve of absorbance against quercetin concentration was prepared. From the regression equation of the standard curve, quercetin equivalents were determined. The results were expressed as percentage $\mathrm{w} / \mathrm{w}$ (mean \pm S.D.). The percentage of TFC in the sample was calculated using the following formula:

$$
\operatorname{TFC}(\% \mathrm{w} / \mathrm{w})=\mathrm{QE} \times \mathrm{V} \times \mathrm{D} \times 10^{-6} \times 100 / \mathrm{W}
$$

where $\mathrm{QE}=$ quercetin equivalents $(\mu \mathrm{g} / \mathrm{ml}) ; \mathrm{V}=$ total volume of sample $(\mathrm{ml}) ; \mathrm{D}=$ dilution factor; $\mathrm{W}=$ sample weight $(\mathrm{g})$.

\section{Evaluation of antioxidant activity by the 1,1-diphenyl-2- picrylhydrazyl assay technique}

The standard procedure of the DPPH method was used to carry out this assay technique [25, 26]. A stock solution of rutin $(100 \mu \mathrm{g} / \mathrm{ml})$ was prepared in methanol. Utilizing the serial dilution method, different concentrations $(2,4,6,8,10$, and $12 \mu \mathrm{g} / \mathrm{ml})$ were prepared. Equal volumes of these aliquots were taken and added to the methanolic DPPH solution. Then, these mixtures were incubated in the dark for $30 \mathrm{~min}$ at room temperature. After the specified time duration, absorbance was taken at $517 \mathrm{~nm}$ using a UV spectrophotometer. Methanol was used as a blank. Test sample solutions were prepared in a similar manner. The free radical scavenging activity of samples was calculated and the $\mathrm{IC}_{50}$ value was determined by plotting a graph between concentrations of samples versus \% inhibition [27].

$$
\text { \%inhibition of free radical }=\left[\mathrm{A}_{\mathrm{C}}-\left(\mathrm{A}_{\mathrm{S}}-\mathrm{A}_{\mathrm{O}}\right)\right] / \mathrm{A}_{\mathrm{C}}
$$$$
\times 100
$$

where Ac = absorbance of control (DPPH); As = absorbance of sample/standard + DPPH; Ao = absorbance of sample / standard without DPPH interaction. The measurements were taken thrice, and the scavenging effect was calculated based on the percentage of DPPH scavenged. $\mathrm{IC}_{50}$ values of the samples for antioxidant activity were calculated using the standard curve of rutin.

\section{Evaluation of antioxidant activity by the hydrogen peroxide scavenging method}

The free radical scavenging activity of plant extract towards hydrogen peroxide was measured by the procedure given by Dehpour. Firstly, $40 \mathrm{mM}$ solution of hydrogen peroxide was prepared by using freshly prepared phosphate buffer $\mathrm{pH}$ 7.4. The concentration of this solution was measured at $560 \mathrm{~nm}$ with the help of a UV spectrophotometer. Then, $0.1 \mathrm{mg} / \mathrm{ml}$ of the extract was added to the hydrogen peroxide solution and absorbance was detected at $560 \mathrm{~nm}$ against a blank solution of phosphate buffer without hydrogen peroxide. The control was prepared with hydrogen peroxide and phosphate buffer without the plant extract. Ascorbic acid was used as a reference standard and phosphate buffer was used as blank for spectroscopic determinations. Finally, the percentage scavenged was determined $[28,29]$.

$$
\begin{aligned}
& \text { Percentage scavenged }[\mathrm{H} 2 \mathrm{O} 2] \\
& \quad=1-\mathrm{Abs}(\text { standard }) / \mathrm{Abs}(\text { control }) \times 100
\end{aligned}
$$

where Abs control was the absorbance of the control (without extract) at $560 \mathrm{~nm}$; Abs sample was the absorbance in the presence of the extract at $560 \mathrm{~nm}$.

\section{Evaluation of antioxidant activity by nitric oxide scavenging method}

Ten millimolar of sodium nitroprusside solution was mixed with $7.4 \mathrm{pH}$ phosphate buffer saline and this mixture was mixed with plant extract in various concentrations (5$200 \mu \mathrm{g} / \mathrm{ml})$. These reaction mixtures were incubated at 300 ${ }^{\circ} \mathrm{C}$ for $2 \mathrm{~h}$. $0.5 \mathrm{ml}$ aliquots were taken from each of these mixtures and further mixed with $0.5 \mathrm{ml}$ of the Griess reagent ( $1 \%$ sulfanilamide in $2 \%$ phosphoric acid and $0.1 \%$ naphthylethylene-diaminedihydrochloride). The absorbance was measured at $550 \mathrm{~nm}$. Percentage inhibition of nitric oxide radical by plant extract and standard antioxidant ascorbic acid was determined [30-32].

$$
\begin{aligned}
& \text { \%Inhibition of free redical } \\
& =\frac{\text { AControl-A Test }}{\text { AControl }} \times 100
\end{aligned}
$$

$\mathrm{A}_{\text {Control }}$ is the absorbance of the control and $\mathrm{A}_{\text {Test }}$ is the absorbance of the sample 


\section{Ex vivo evaluation of anti-cataract activity of ethanolic extract of C. maritima}

To perform this study, fresh goat eyeballs were collected from the nearby slaughterhouse and immediately carried to the laboratory and kept at $0-4{ }^{\circ} \mathrm{C}$. Then, lenses were carefully extracted by utilizing extracapsular extraction technique and incubated in laboratory prepared fresh artificial aqueous humor (sodium chloride: $140 \mathrm{mM}$, potassium chloride: $5 \mathrm{mM}$, magnesium chloride: $2 \mathrm{mM}$, sodium bicarbonate: $0.5 \mathrm{mM}$, sodium dihydrogen phosphate: $0.5 \mathrm{mM}$, calcium chloride: $0.4 \mathrm{mM}$, and glucose: $5.5 \mathrm{mM}$ ) at room temperature. The $\mathrm{pH}$ of the medium was 7.8. To prevent the growth of microorganisms, 100 $\mu \mathrm{g} / \mathrm{ml}$ streptomycin and $100 \mathrm{IU} / \mathrm{ml}$ penicillin were added to the medium [19].

\section{Study groups}

1. Group I $(n=6)$ Normal control lens incubated in artificial aqueous humor

2. Group II $(n=6)$ Lens incubated in artificial aqueous humor containing $100 \mu \mathrm{M}$ sodium selenite.

3. Group III $(n=6)$ Lens incubated in artificial aqueous humor containing $100 \mu \mathrm{M}$ sodium selenite and $150 \mu \mathrm{g} / \mathrm{ml}$ of ethanolic extract of the plant.

4. Group IV $(n=6)$ Lens incubated in artificial aqueous humor containing $100 \mu \mathrm{M}$ sodium selenite and $300 \mu \mathrm{g} / \mathrm{ml}$ of ethanolic extract of the plant.

\section{Morphological examination of the lens}

For the determination of the anti-cataract effect of the plant, lenses of each group were incubated for $72 \mathrm{~h}$ in their respective culture mediums. Then, visual inspection of lenses for opacity and transparency was carried out by suitably placing lenses in a wired mesh to see the number of squares in the mess through the posterior surface of lenses touching the mesh. The grading system as shown below was used to determine the results [33].

0 : Indicates complete absence of opacity and clear visibility of all the squares covered by the lens.

+: Indicates a slight degree of opacity in which maximum squares covered by the lens are visible with minimum clouding

++ : Indicates presence of diffuse opacification in which mesh squares are faintly visible

+++ : Indicates presence of extensive thick opacification in which nothing is visible through the lens

Preparation of lens homogenate for the determination of total protein, sodium, and potassium

After 3 days of incubation, $10 \%$ of lens homogenates from each group were prepared in $0.1 \mathrm{M}$ sodium phosphate buffer of $\mathrm{pH}$ 7.4. Then, respective homogenates were centrifuged by using a refrigerated centrifuge at 10 ,
$000 \mathrm{~g}$ for $30 \mathrm{~min}$ at $4{ }^{\circ} \mathrm{C}$. The supernatant was collected and used for the estimation of various biochemical parameters [34].

\section{Estimation of various biochemical parameters}

Biochemical parameters such as total protein content, sodium, and potassium levels in the lens homogenates were estimated for the determination of the anti-cataract activity of the ethanolic plant extract. Total protein content was measured by using Lowry's method and the amount of sodium and potassium was estimated with the help of flame photometry [34].

\section{Statistical analysis}

All the results are expressed as mean ${ }^{\mathrm{n}} \pm$ S.D. for three parallel measurements $(\mathrm{n}=3)$. Results were processed by using Microsoft excel 2019 and SPSS student version 16. The statistical significance of the difference between groups for the various treatments is analyzed by oneway ANOVA followed by the post hoc Tukey test. $p<$ $0.05, p<0.01$, and $p<0.001$ were considered statistically significant.

\section{Results}

In this study, the ethanolic extract of the plant C. maritima was used for the determination of TPC, TFC, antioxidant activity, and ex vivo anti-cataract activity using goat eye lenses to know its potential for the effective treatment of cataract. So far, in India, experimental studies have been conducted by a group of scientists, Anitha et al., for the determination of anti-cataract activity of this plant because of its antioxidant potential. But, in the present study, this is the very first time the authors have tried to determine the TPC, TFC, and in vitro antioxidant activity of $C$. maritima by techniques such as $\mathrm{DPPH}$, hydrogen peroxide, nitrous oxide, and estimation of protein and various ions in the lens homogenates. Literature studies greatly revealed the extensive use of this plant in homeopathic systems of medicines for the prevention and early onset of cataract. The anti-cataract activity of this plant is due to the presence of antioxidants such as phenols and flavonoids which help in combating oxidative stress which is the underlying cause of cataractogenesis in most of the cases. Therefore, this experimental study was conducted to determine the total phenolic and flavonoid content of this plant along with experimental antioxidant and anti-cataract activities.

\section{Preliminary phytochemical analysis}

The phytochemical analysis of the ethanolic extract of the plant C. maritima has revealed the presence of various constituents such as alkaloids, carbohydrates, flavonoids, and others which are tabulated below in Table 1. 
Table 1 Preliminary phytochemical analysis of ethanolic extract of plant Cineraria maritime

\begin{tabular}{ll}
\hline Class of phytoconstituents & $\begin{array}{l}\text { Ethanolic extract of Plant } \\
\text { Cineraria maritima }\end{array}$ \\
\hline Alkaloids & + \\
Carbohydrates & + \\
Anthraquinone glycosides & - \\
Cyanogenetic glycosides & - \\
Cardiac glycosides & - \\
Steroids / Triterpenoids & $-/+$ \\
Saponins & + \\
Coumarins & - \\
Flavonoids & + \\
Tannins & + \\
Proteins & + \\
Fixed oils & - \\
\hline
\end{tabular}

+ present, - absent

Total phenolic and flavonoid content

As shown in Table 2, TPC was found to be $6.31 \pm 0.06$ $\% \mathrm{w} / \mathrm{w}$ which clearly signifies the high antioxidant potential of this plant. In this study, the calibration curve of gallic acid (Fig. 1) was plotted to determine the value of TPC by using the calibration curve equation $\mathrm{Y}=$ $0.0053 X+0.0107$ with an $R^{2}$ value 0.9967 where $Y$ represents absorbance and $\mathrm{X}$ represents the concentration of gallic acid in $\mu \mathrm{g} / \mathrm{ml}$ which is expressed as \% $\mathrm{w} / \mathrm{w}$. TFC was determined by using quercetin as a standard with the help of the aluminum chloride method spectrophotometrically. For this purpose, the calibration curve of quercetin (Fig. 2) was drawn to obtain a mathematical equation $Y=0.0048+0.016$ with an $R^{2}$ value of 0.998 . With this equation, the value of TFC was found to be $2.14 \pm 0.09 \% \mathrm{w} / \mathrm{w}$, which shows the antioxidant potential of the plant under consideration.

\section{Antioxidant activity}

Antioxidant activity was performed by three different methods such as DPPH, hydrogen peroxide, and nitric oxide. In the DPPH assay technique, rutin was used as a standard (Fig. 3) for the determination of the antioxidant potential of $C$. maritima. Results obtained with the DPPH method are given in Table 3. From the DPPH method, the IC50 value of the standard compound was found to be $5.45 \mu \mathrm{g} / \mathrm{ml}$ and that of the ethanolic extract of the plant was $73.26 \mu \mathrm{g} / \mathrm{ml}$ (Fig. 4). The hydrogen peroxide method was the second method which was used for the determination of antioxidant potential. In this method, ascorbic acid was used as a standard which showed an $\mathrm{IC}_{50}$ value of $0.89 \mathrm{mg} / \mathrm{ml}$, while the $\mathrm{IC}_{50}$ value of the ethanolic extract of the plant was found to be $1.30 \mathrm{mg} / \mathrm{ml}$. Results obtained with this method are shown in Table 3 and Fig. 5 which clearly revealed the antioxidant potential of this plant. The nitric oxide scavenging method was also used for the determination of antioxidant activity. The results obtained with this method are shown in Table 3 and Fig. 6. Ascorbic acid was used as a standard in this method which showed the IC50 value of $27.03 \mu \mathrm{g} / \mathrm{ml}$ and the IC50 value for the ethanolic plant extract was found to be $121.85 \mu \mathrm{g} / \mathrm{ml}$. Thus, results obtained with all the techniques show strong evidence of the antioxidant potential of the plant CM.

\section{Ex vivo anti-cataract activity of ethanolic extract of the plant}

Results of this study are obtained in a photographic manner which are shown in different figures (Figs. 10, 11,12 , and 13). A comparison of photographs obtained for various groups under study clearly revealed the anticataract activity of C. maritima.

\section{Estimation of biochemical parameters Estimation of protein present in lens homogenate}

The amount of protein present in group I (normal control lenses) was found to be $3.17 \pm 0.01 \mathrm{~g} / \mathrm{dl}$ as compared to $1.35 \pm 0.03 \mathrm{~g} / \mathrm{dl}$ in the cataract-induced group II and $2.65 \pm 0.02 \mathrm{~g} / \mathrm{dl}$ and $3.01 \pm 0.01 \mathrm{~g} / \mathrm{dl}$ in cataracttreated group III containing $150 \mathrm{ug} / \mathrm{ml}$ and cataracttreated group IV containing $300 \mu \mathrm{g} / \mathrm{ml}$ plant extract respectively (Table 5 and Fig. 7).

\section{Estimation of sodium and potassium present in lens homogenate}

Data obtained from this study is shown in Table 5 . The concentration of $\mathrm{Na}^{+}$ions, i.e., $101.2 \pm 0.03 \mu \mathrm{g} / \mathrm{ml}$ was found to be least in group I as compared to $232.5 \pm 0.04$ $\mu \mathrm{g} / \mathrm{ml}$ in group II (Fig. 8). The cataract-treated groups III and IV showed a decrease in the concentration of $\mathrm{Na}^{+}$ions in a dose-dependent manner. Further, the concentration of $\mathrm{K}^{+}$ions was estimated about $11.6 \pm 0.01$ $\mu \mathrm{g} / \mathrm{ml}$ in group I, whereas $5.9 \pm 0.03 \mu \mathrm{g} / \mathrm{ml}$ was determined in cataract-induced group II (Fig. 9). Other groups III and IV showed an increase in concentration with the increase in the dose of the extract.

Table 2 Total phenolic and flavonoid content in the ethanolic extract of plant Cineraria maritima

\begin{tabular}{|c|c|c|}
\hline Test sample & Total phenolic content $(\% w / w)$ mean $^{n} \pm$ S.D. & Total flavonoid content $(\% \mathrm{w} / \mathrm{w}) \operatorname{mean}^{\mathrm{n}} \pm$ S.D. \\
\hline (Ethanolic plant extract) F1 & $6.31 \pm 0.06$ & $2.14 \pm 0.09$ \\
\hline
\end{tabular}




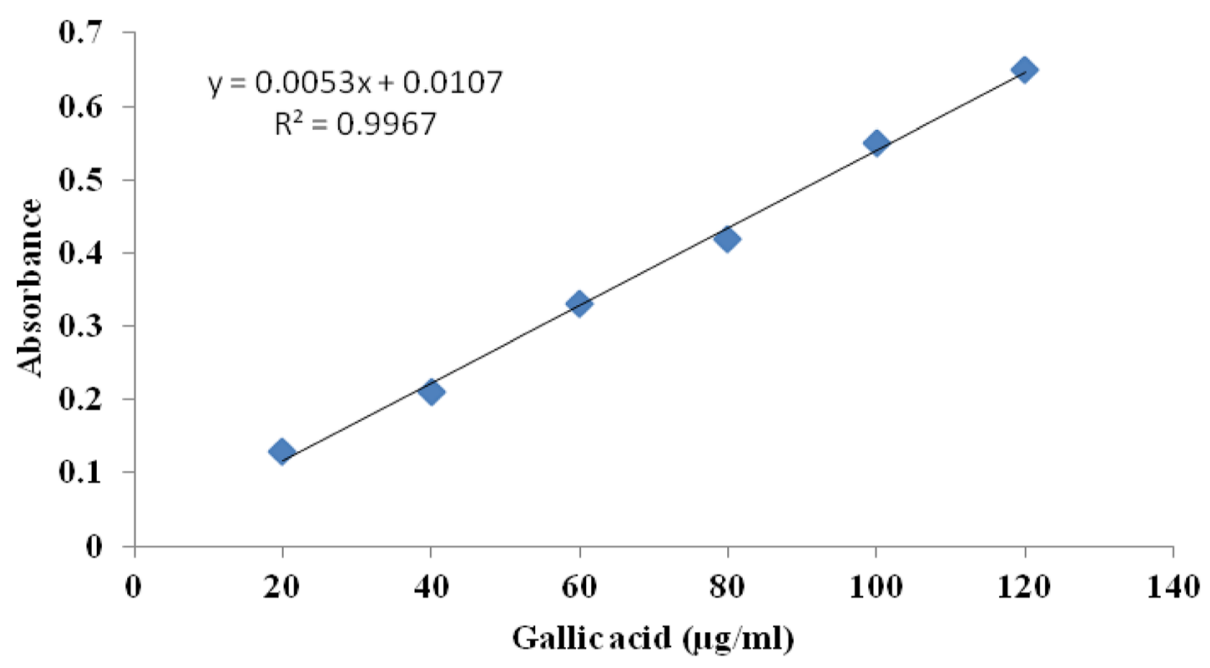

Fig. 1 Calibration curve of gallic acid

\section{Discussion}

With much revolutionization of science and technology, the twenty-first century has witnessed great use of herbs and herbal-based products for the effective treatment of almost all severe diseases and disorders which impose an excessively high life-threatening toll on the health of human beings. Knowing the great potential of herbs, nanotechnology, the science which deals with things in nanodimensions, has also entered into the designing of herbal-based drug delivery systems. Scientists believe that the development of a single system based on the dual aspects of nano and herbs to get maximum absorption due to its nano size and least or no toxicity because of its herbal origin can be of much significance to conquer these deadly diseases [35]. One more reason why nowadays the use of herbs and herbal-based drugs has been increasing enormously in modern era therapeutics as compared to synthetic counterparts is the significant antioxidant potential of the herbs. A number of experimental studies claim that high oxidative stress is the main underlying cause of most of the serious diseases [36]. Cataract which is characterized by opacification of the lenses due to the precipitation of natural crystalline protein present in the lenses is one such disease for which the main underlying cause is OS. However, for the effective treatment of cataract, modern surgical techniques are available, but at the same time, the severe postoperative complication cannot be neglected. Socioeconomic factors are some of the other key factors which also play a profound role as major obstacles in the treatment [4]. Thus, the development of an approach based on an antioxidant mechanism other than surgery is a great call of the hour so that the onset of cataract can be stopped or at least delayed. Keeping this

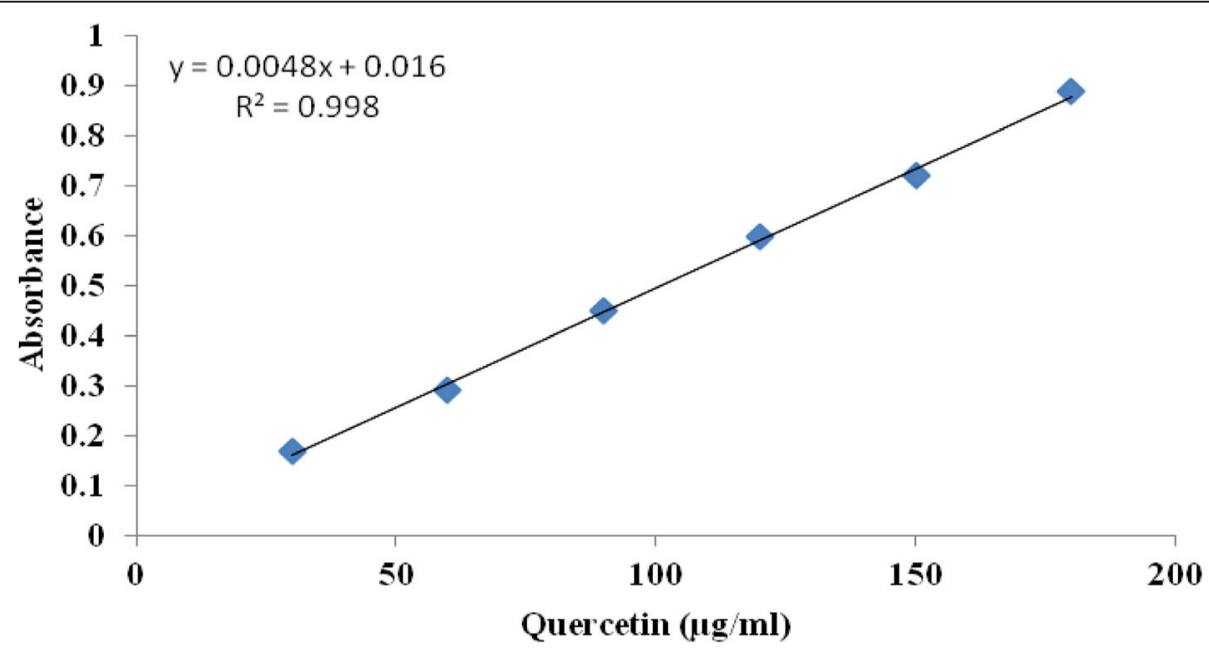

Fig. 2 Calibration curve of quercetin 


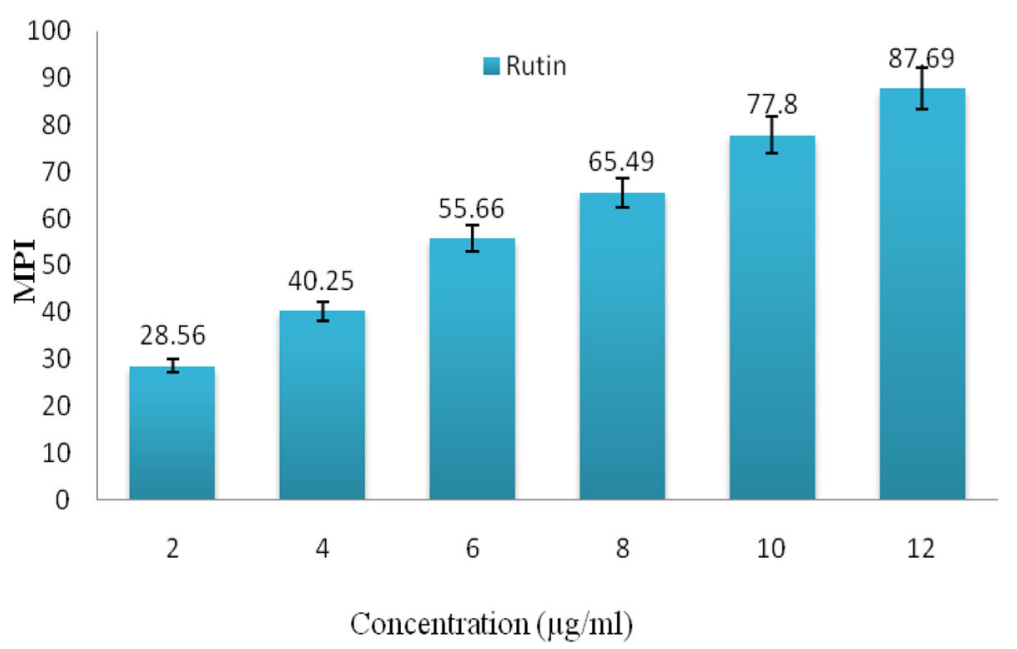

Fig. 3 Graph showing mean percentage inhibition of DPPH by rutin

fact in mind, this research work has been conducted to determine the antioxidant and anti-cataract activity of $C$. maritima by using different techniques and an ex vivo cataract model so that this plant can be utilized for the development of some novel dosage forms. Initially, studies such as TPC and TFC were done. For the determination of TPC in the ethanolic extract of plant material, Folin Ciocalteu's method was used with gallic acid as a standard. This method is based on the principle of the formation of molybdenum blue when the process of oxidation occurs with the phenolic groups present in the plant extract. Phenolic compounds possess redox properties which attribute to their antioxidant property. In these compounds, the hydroxyl group is known to play a significant role in the scavenging of free radicals thus this parameter can be efficiently used as a measure for the antioxidant potential of plants. TFC was estimated by using quercetin as a standard. The principle of this method is based on the formation of acid-stable complexes by aluminum chloride with flavones and flavonols present in plants. When aluminum chloride comes in contact with the C-4 keto group and C-3 and C-5 hydroxyl groups of flavones and flavanols present in plant samples, it forms acid-stable complexes which can be utilized for the determination of the total flavonoid content of plant samples. It is also capable of forming acidlabile complexes with the ortho-dihydroxyl groups present in A or B rings of flavonoids. Experimental studies revealed the presence of their high amount (TPC, $6.31 \pm 0.06 \% \mathrm{w} / \mathrm{w}$ and TFC, $2.14 \pm 0.09 \% \mathrm{w} / \mathrm{w})$ which collectively plays a significant role in its antioxidant potential. Thus, it can be said that the high antioxidant potential of this plant is due to the presence of a considerable amount of phenolic and flavonoid content which also plays a profound role in its strong anti- cataract activity. For the estimation of antioxidant study, three different techniques, namely DPPH, hydrogen peroxide, and nitric oxide methods, were used because each single technique is based on different scavenging mechanisms and utilizes a completely different experimental procedure which varies with respect to chemical reaction and reaction time, thus helping in better quantification of the antioxidant potential of the plant under consideration. The DPPH assay technique is based on the simple principle that a DPPH molecule behaves as a stable free radical due to the presence of a spare electron on the molecule which remains delocalized over the entire molecule [18]. This delocalization of the spare electron prevents the dimerization of the DPPH molecule and also results in the deep violet color with a characteristic band of $517 \mathrm{~nm}$ in methanol and $520 \mathrm{~nm}$ in ethanol when detected spectrophotometrically. On addition of a substance which can donate its hydrogen to the DPPH molecule, this violet color reduces due to the reduction of DPPH and oxidation of substance under consideration. In this study, rutin was used as a standard. The \% inhibition value was found to be low in comparison with standard compounds, but as per the standard values for the antioxidant potential of plants, it belongs to the active category and speaks about the high antioxidant potential of the plant. Also, the relationship between the different concentrations of plant extract and percentage inhibition showed a high $R^{2}$ value (Table 4) which signifies a proportional relationship between the two variables showing linearity of the curve and increase in antioxidant activity. The increase in the value of percentage inhibition with the increasing concentration of plant extract revealed its antioxidant potential. The hydrogen peroxide technique was also used which is based on the principle of neutralization of $\mathrm{H}_{2} \mathrm{O}_{2}$ into water when 
Table 3 Table showing data of antioxidant activity by various methods

\begin{tabular}{|c|c|c|c|}
\hline Treatment & Concentration $(\mu \mathrm{g} / \mathrm{ml})$ & Mean $^{n}$ percentage inhibition of radical \pm S.D. & $I C_{50}$ values $(\mu \mathrm{g} / \mathrm{ml})$ \\
\hline \multicolumn{4}{|l|}{ DPPH Method } \\
\hline \multirow[t]{6}{*}{ Rutin } & 2 & $28.56 \pm 0.321$ & 5.45 \\
\hline & 4 & $40.25 \pm 0.450$ & \\
\hline & 6 & $55.66 \pm 0.789$ & \\
\hline & 8 & $65.49 \pm 0.630$ & \\
\hline & 10 & $77.80 \pm 0.499$ & \\
\hline & 12 & $87.69 \pm 0.652$ & \\
\hline \multirow[t]{6}{*}{ F1 } & 5 & $16.55 \pm 0.458$ & 73.26 \\
\hline & 10 & $18.24 \pm 0.658$ & \\
\hline & 20 & $25.65 \pm 0.258$ & \\
\hline & 40 & $36.22 \pm 0.459$ & \\
\hline & 80 & $55.01 \pm 0.658$ & \\
\hline & 160 & $89.57 \pm 0.448$ & \\
\hline \multicolumn{4}{|c|}{ Hydrogen peroxide method } \\
\hline \multirow[t]{6}{*}{ Ascorbic acid } & 0.0625 & $16.25 \pm 0.658$ & 0.89 \\
\hline & 0.125 & $20.50 \pm 0.785$ & \\
\hline & 0.25 & $26.44 \pm 0.985$ & \\
\hline & 0.50 & $35.69 \pm 0.756$ & \\
\hline & 1 & $56.52 \pm 0.325$ & \\
\hline & 2 & $91.25 \pm 0.752$ & \\
\hline \multirow[t]{6}{*}{ F1 } & 0.0625 & $11.24 \pm 0.550$ & 1.30 \\
\hline & 0.125 & $13.49 \pm 0.456$ & \\
\hline & 0.25 & $17.98 \pm 0.325$ & \\
\hline & 0.50 & $25.64 \pm 0.489$ & \\
\hline & 1 & $42.66 \pm 0.653$ & \\
\hline & 2 & $70.55 \pm 0.324$ & \\
\hline \multicolumn{4}{|c|}{ Nitric oxide method } \\
\hline \multirow[t]{6}{*}{ Ascorbic acid } & 10 & $45.14 \pm 0.658$ & 27.03 \\
\hline & 20 & $49.58 \pm 0.789$ & \\
\hline & 40 & $52.32 \pm 0.654$ & \\
\hline & 80 & $59.44 \pm 0.125$ & \\
\hline & 160 & $72.44 \pm 0.315$ & \\
\hline & 320 & $96.47 \pm 0.458$ & \\
\hline \multirow[t]{6}{*}{ F1 } & 10 & $30.14 \pm 0.985$ & 121.85 \\
\hline & 20 & $32.25 \pm 0.456$ & \\
\hline & 40 & $36.44 \pm 0.325$ & \\
\hline & 80 & $43.55 \pm 0.458$ & \\
\hline & 160 & $58.12 \pm 0.659$ & \\
\hline & 320 & $82.44 \pm 0.311$ & \\
\hline
\end{tabular}

Values are expressed as mean ${ }^{n} \pm$ S.D. for $n=3$

reacts with the electron donated by the plant extract due to its phenolic content. It was observed from the results of this study that the ethanolic extract of $C$. maritima scavenged $\mathrm{H}_{2} \mathrm{O}_{2}$ in a dose-dependent manner thus possessing significant antioxidant activity. The nitric oxide method is based on the principle of determination of the nitrite ion using the Griess reagent. At physiological $\mathrm{pH}$ 7.2, sodium nitroprusside is known to 


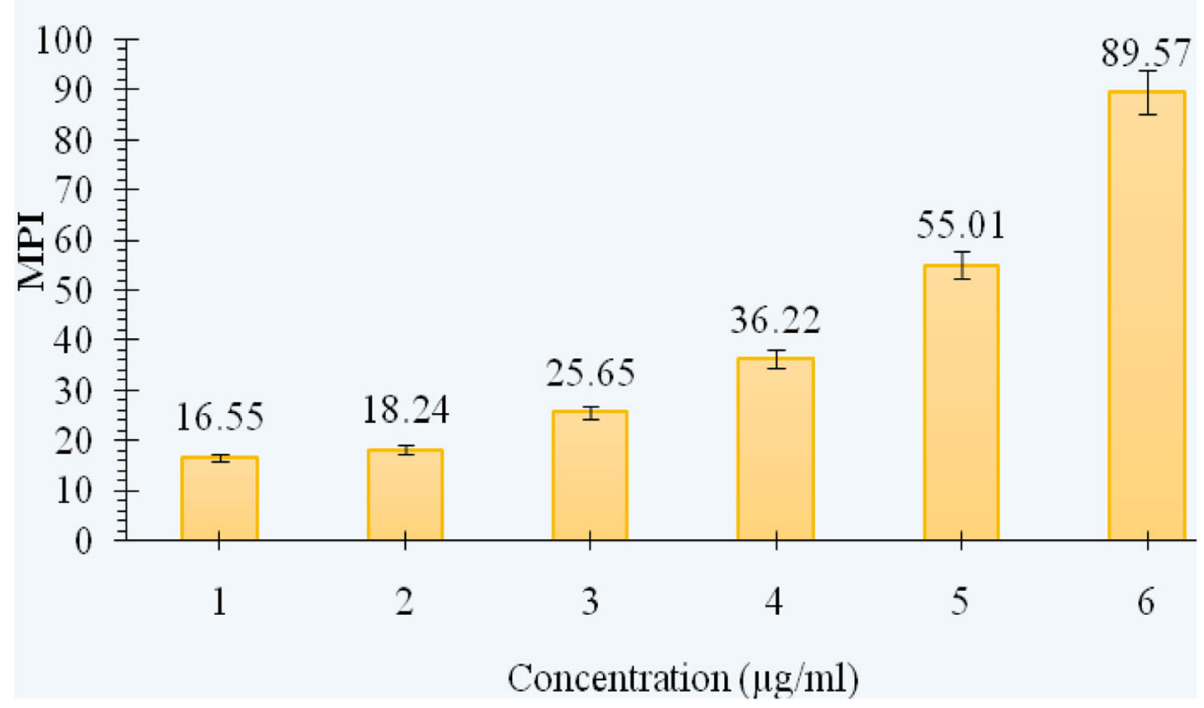

Fig. 4 Graph showing mean percentage inhibition of DPPH by ethanolic plant extract (F1)

decompose into nitric oxide in an aqueous solution and produces nitrite ions when reacting with oxygen. Results of antioxidant activity (Table 3) based on the determination of IC50 values by all the applied techniques clearly gave strong evidence regarding the great antioxidant potential of this plant because of its high free radical scavenging action and laid a strong foundation for its time immemorial use in the treatment of cataract via the management of OS which is the main culprit in the onset of this disease. The OS-induced ex vivo cataract model was used to determine the anti-cataract potential of this plant. For this purpose, goat eye lenses were collected from the nearby slaughterhouse and various study groups were made. In this study, a total of 24 lenses were used which were divided into four different groups. On the basis of thorough visual inspection, lenses belonging to group I (Fig. 10) were designated with grade 0 because these were found to maintain complete transparency and clarity throughout their incubation period. Lenses of group II (Fig. 11) were graded as +++ because sodium selenite leads to severe oxidative stress due to excessively high production of reactive oxygen species (ROS) which is the major cause of lens damage and development of cataract. Lenses coming under group III (Fig. 12) were graded as + because lenses were almost clear with very slight opacity and those belonging to group IV (Fig. 13) were graded as 0 because all the lenses exhibited complete transparency. The reason

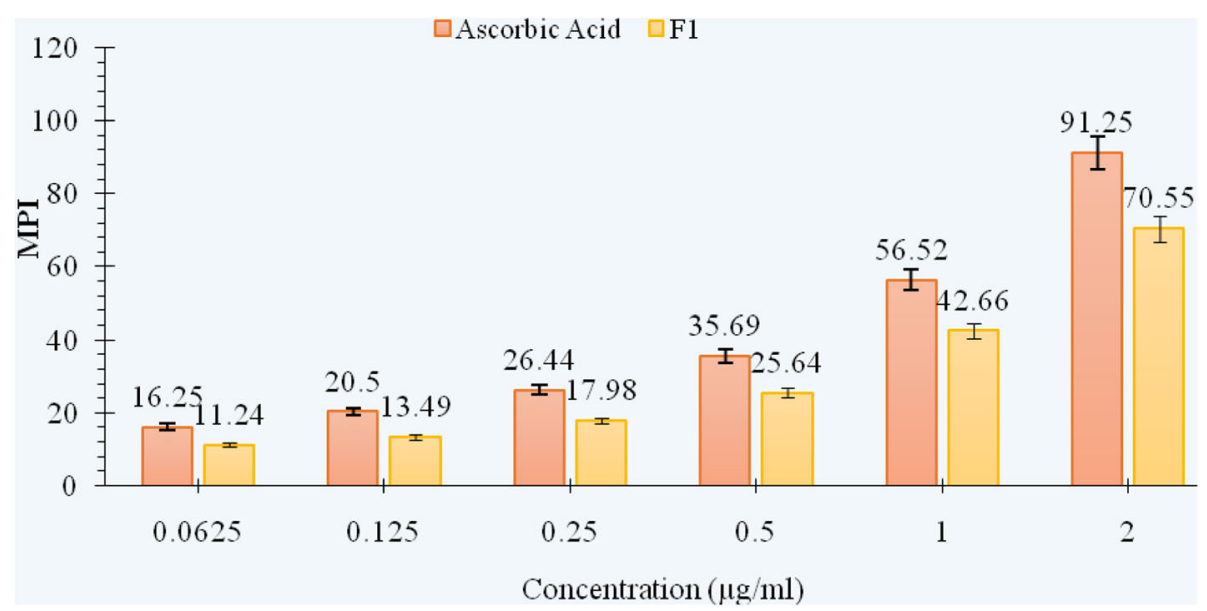

Fig. 5 Graph showing mean percentage inhibition of hydrogen peroxide by ascorbic acid and plant extract F1 
$\square$ Ascorbic Acid $\square \mathrm{F} 1$

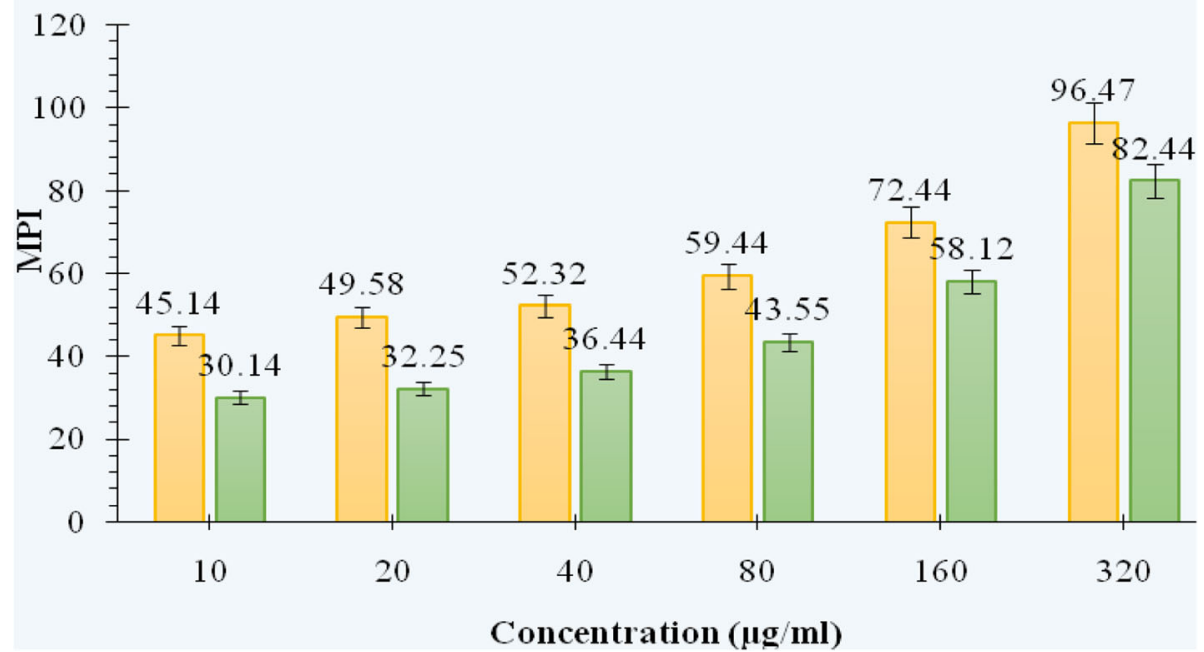

Fig. 6 Graph showing mean percentage inhibition of nitric oxide by ascorbic acid and plant extract F1

attributed to the difference in the results of various groups is the medium of their incubation which gives a high degree of assurance that OS is the main cause of cataract. The use of plant extract decreases OS in group III and group IV in a dose-dependent manner by preventing free radicals generated by sodium selenite and results in the clarity and transparency of lenses almost similar to group I. These results clearly showed that the ethanolic extract of $C$. maritima possesses promising anti-cataract activity due to reduction in OS because of high levels of phenolic and flavonoid contents as reported by Grace et al. The reduction in OS due to the decrease in selenite-induced free radical generation which further decreases precipitation of protein present in the crystalline lens may be the plausible mechanism of action of C. maritima for the prevention of cataract. Further, biochemical studies (Table 5) conducted for the determination of protein and various ions present in the lenses incubated in different conditions as per their study design strongly supports the high anti-cataract potential of C. maritima. A total protein content (TPRC) study showed that the amount of protein present in the lenses incubated in artificial aqueous humor (group I) was found to be significantly high as compared to lenses of the cataract-induced group because OS results in precipitation of lens protein at $p<0.001$. The lenses of the

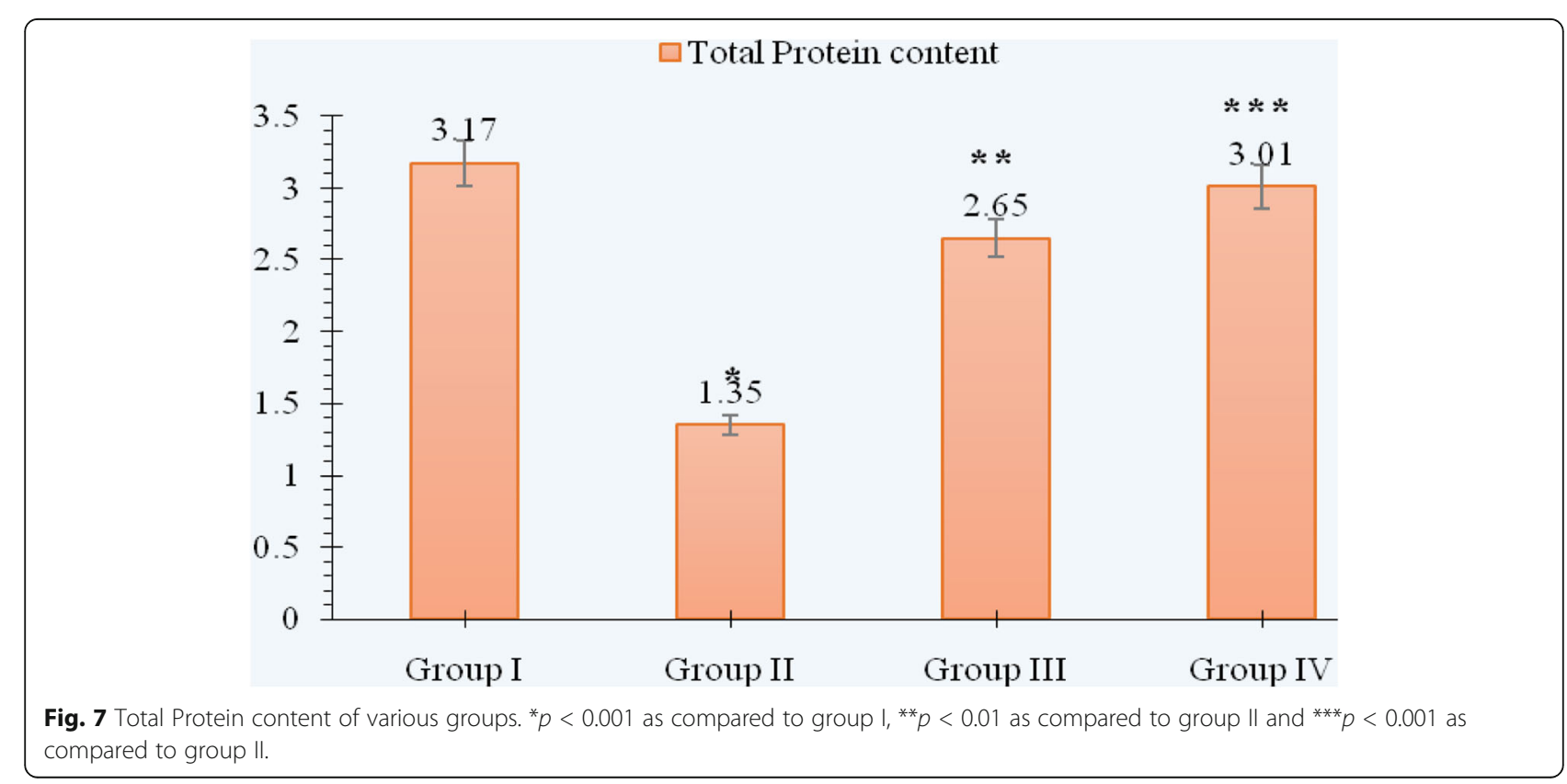




\section{$\square$ Sodium levels}

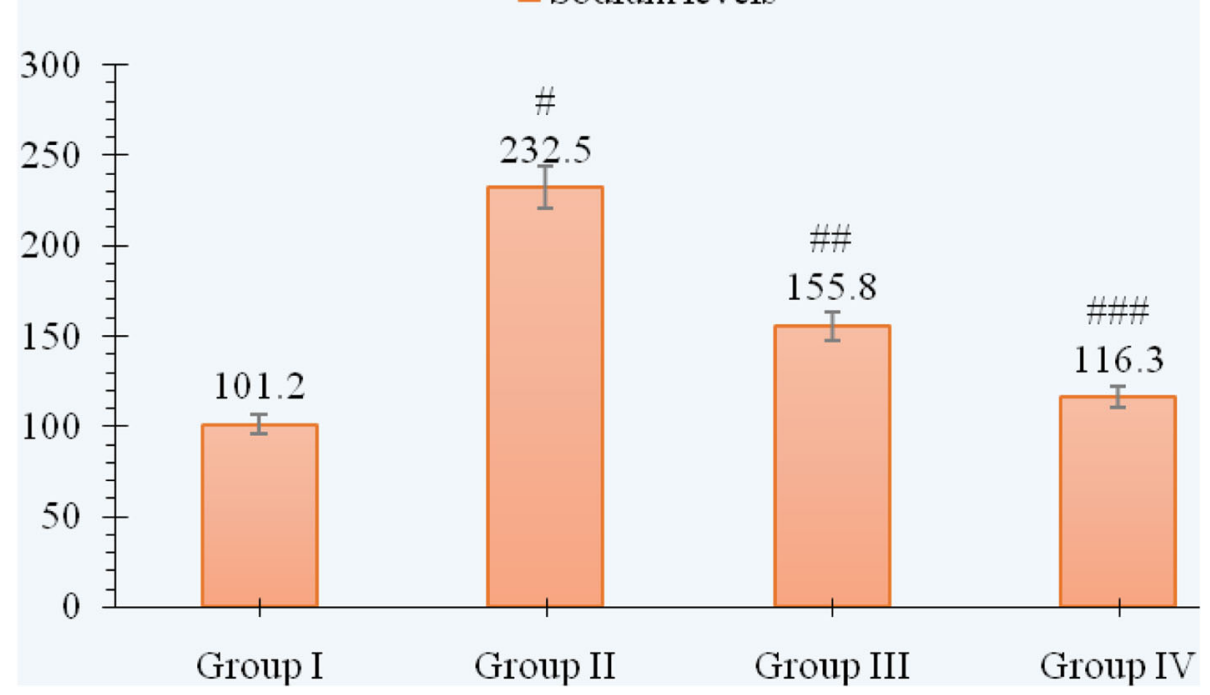

Fig. 8 Sodium levels of various groups. ${ }^{\#}<0.001$ as compared to group I, ${ }^{\# \#} p<0.05$ as compared to group II and ${ }^{\# \#} p<0.01$ as compared to group II

cataract-treated groups (group III and group IV) showed an increase in protein content in a dose-dependent manner thus revealing the high anti-cataract effect of $C$. maritima $(p<0.01$ for group III as compared to group II and $p<0.001$ for group IV as compared to group II). The reason of the increase in the concentration of protein with plant extract may be attributed to the presence of phenols and flavonoids in the plant extract. Results and observations of the study conducted to estimate the concentration of ions present in lens homogenates suggested a high concentration of $\mathrm{Na}^{+}$and low concentration of $\mathrm{K}^{+}$ions in the cataract-induced group II $(p<$ 0.001 as compared to group I), whereas lenses of group I and the cataract-treated groups III and IV showed an increase in the concentration of $\mathrm{K}^{+}$ions $(p<0.05$ for group III as compared to group II and $p<0.001$ for group IV as compared to group II) and decrease in $\mathrm{Na}^{+}$ ions $(p<0.05$ for group III as compared to group II and $p<0.01$ for group IV as compared to group II). This alteration in the ratio of concentration from normal lenses

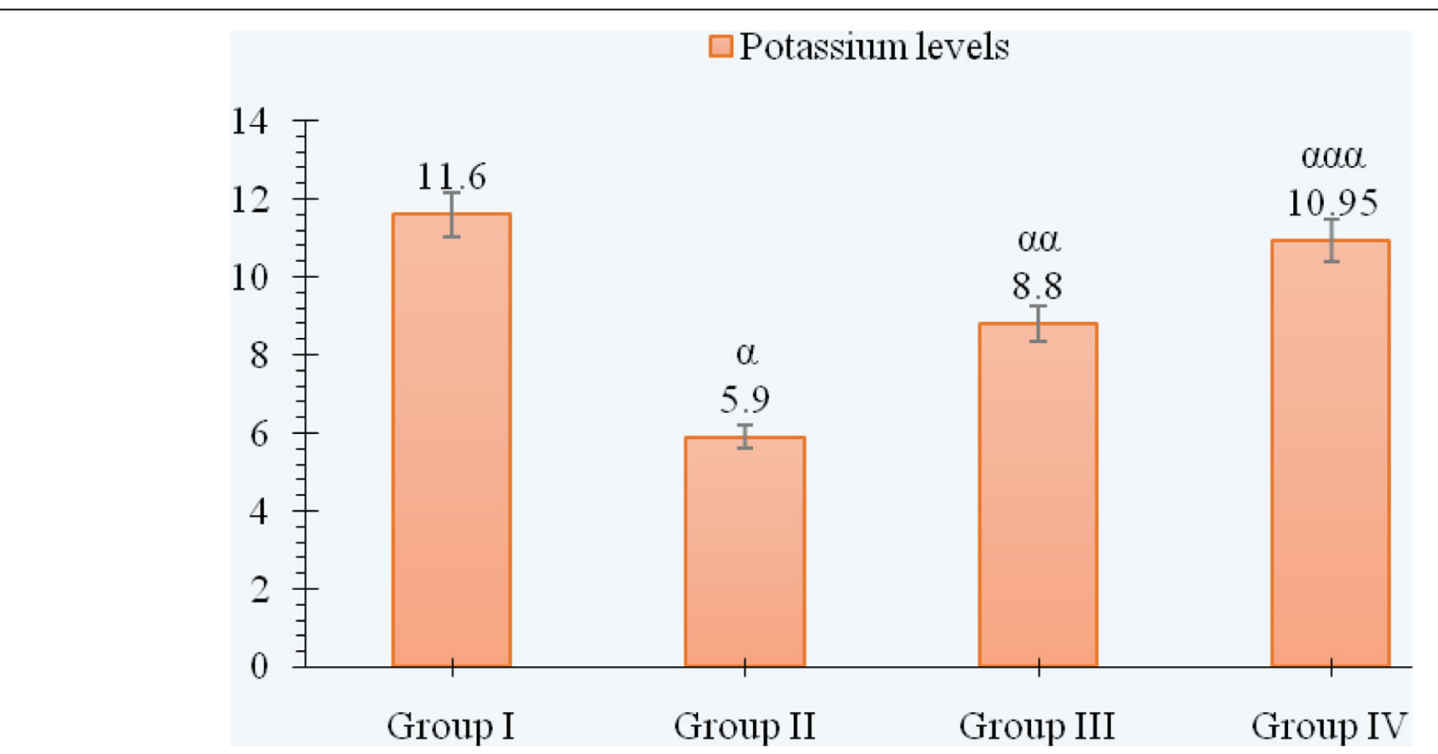

Fig. 9 Potassium levels of various groups. ${ }^{a} p<0.001$ as compared to group I, aa $p<0.05$ as compared to group II and ${ }^{\text {aaa }} p<0.001$ as compared to group II 
Table 4 Table showing data of $R^{2}$ value and linear regression equation of various methods used for the determination of antioxidant activity of plant extract F1

\begin{tabular}{lll}
\hline Methods & $\mathrm{R}^{2}$ value & Equation \\
\hline DPPH & & \\
$\quad$ Rutin & 0.996 & $\mathrm{Y}=5.973 \mathrm{X}+17.42$ \\
$\quad$ Plant extract F1 & 0.996 & $\mathrm{Y}=0.471 \mathrm{X}+15.44$ \\
Hydrogen peroxide & & \\
$\quad$ Ascorbic acid & 0.996 & $\mathrm{Y}=38.27 \mathrm{X}+15.98$ \\
$\quad$ Plant extract F1 & 0.998 & $\mathrm{Y}=30.68 \mathrm{X}+10.12$ \\
Nitric oxide & & \\
$\quad$ Ascorbic acid & 0.995 & $\mathrm{Y}=0.161 \mathrm{X}+45.64$ \\
Plant extract F1 & 0.997 & $\mathrm{Y}=0.168 \mathrm{X}+29.45$ \\
\hline
\end{tabular}

and accumulation of $\mathrm{Na}^{+}$in cataract induced group is probably due to impairment of $\mathrm{Na}^{+} \mathrm{K}^{+}$-ATPase activity which decreases TPRC in the lenses resulting in their opacity and development of cataract. The dose of plant extract has a significantly high influence in the concentration of ions present in the treated groups (group III and group IV). With the increase in the concentration of plant extract, a remarkable decrease in the concentration of $\mathrm{Na}^{+}$and an increase in the concentration of $\mathrm{K}^{+}$ions in group IV as compared to group III was reported. This substantial increase in the concentration of $\mathrm{K}^{+}$ions with the dose of plant extract may be due to the presence of a high amount of potassium present in C. maritima as determined by J. Burdon-Cooper with the spectroscopic studies. One-way ANOVA followed by the post hoc Tukey test was applied for the analysis and all the results were found to be statistically significant at $p<0.05, p<$ 0.01 and $p<0.001$. Results of our study also confirm the

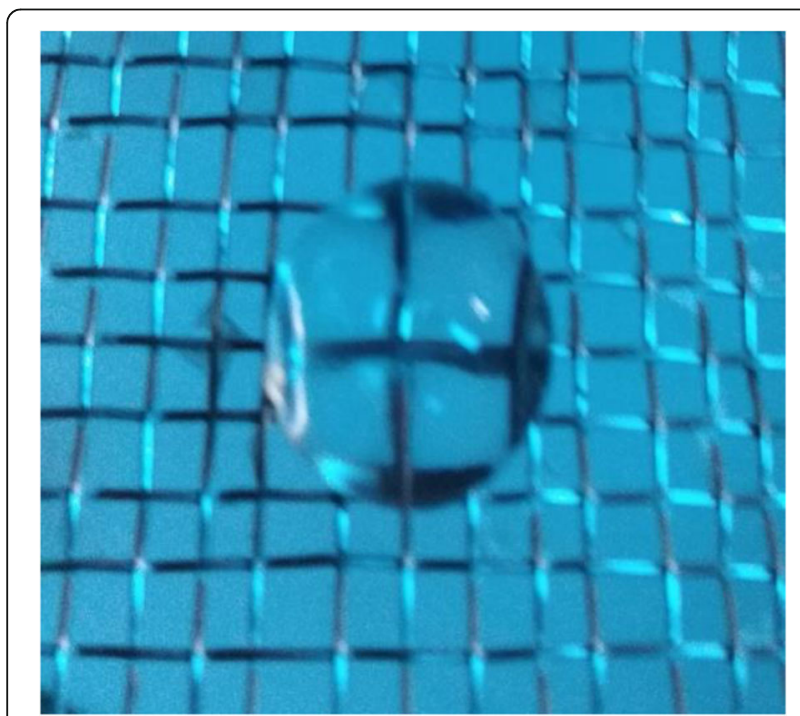

Fig. 10 Group I (normal control)

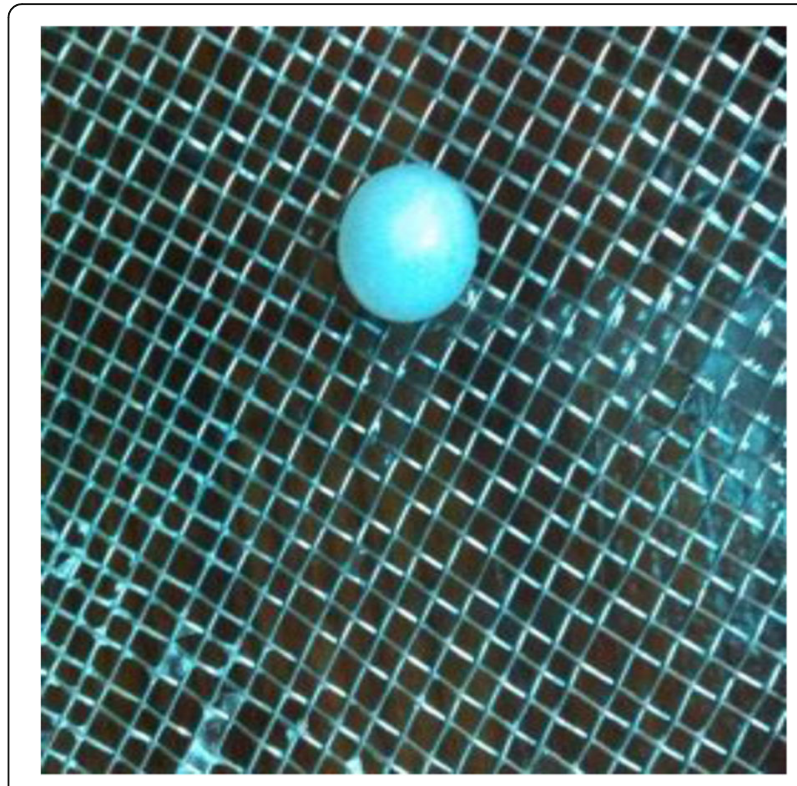

Fig. 11 Group II (cataract induced)

ability of this plant in a noteworthy way to combat cataract. This research elucidates a multipronged strategy to support the substantial anti-cataract activity of C.maritima due to a considerable amount of phenols and flavonoids found, as well as its contribution in increasing protein and potassium concentrations in cataractous lens which essentially maintains lens transparency. Thus, it has a propensity to prevent or delay the onset of cataract by restricting the insolubilization of lens protein, maintaining the normal activity of natural lens

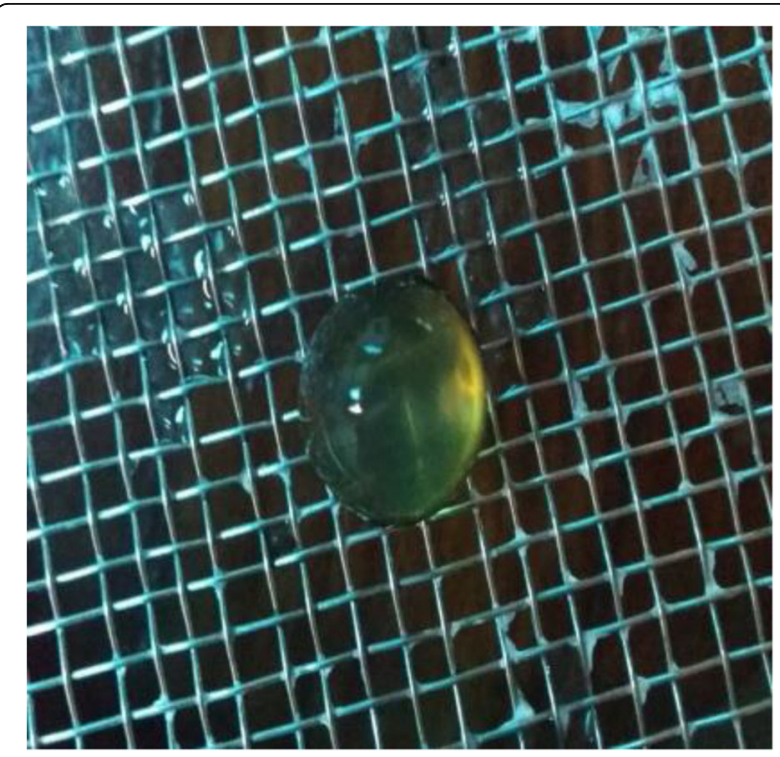

Fig. 12 Group III (cataract treated with $150 \mu \mathrm{g} / \mathrm{ml}$ of ethanolic extract) 


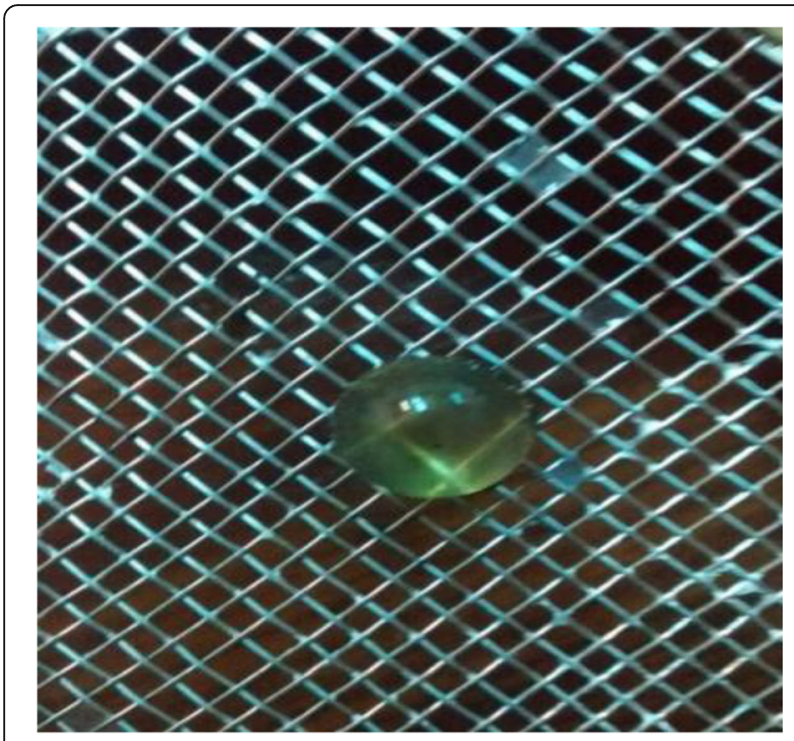

Fig. 13 Group IV (cataract treated with $300 \mu \mathrm{g} / \mathrm{ml}$ of ethanolic extract)

antioxidants and optimum concentration of required ions for the normal functioning of lens, so giving credence to this approach of treatment for age-related or senile cataract. Therefore, our research findings firmly endorse previous investigative studies and its wellprescribed use in homeopathy in treating or delaying the onset of cataract as suggested by Anitha et al. A study related to the global marketing scenarios for the presently existing dosage form of this plant clearly revealed the availability of its solution form which has limitations due to the complex anatomical and physiological functions and barriers of the eye [18, 37]. All these shortcomings of simple solution dosage forms limit the maximum outcomes that can be obtained with this potential herbal candidate. Keeping in mind all the abovementioned limitations, we believe that this magical remedy requires special attention for the development of its novel dosages forms to get maximum advantages.

Table 5 Table showing levels of different ions in normal, cataract induced and cataract treated groups

\begin{tabular}{llll}
\hline Groups & $\begin{array}{l}\text { Total protein } \\
\text { content }(\mathrm{g} / \mathrm{dl} \\
\pm \mathrm{S} . \mathrm{D} .)\end{array}$ & $\begin{array}{l}\text { Sodium levels } \\
(\mu \mathrm{g} / \mathrm{ml} \pm \text { S.D. })\end{array}$ & $\begin{array}{l}\text { Potassium levels } \\
(\mu \mathrm{g} / \mathrm{ml} \pm \text { S.D. })\end{array}$ \\
\hline Group I & $3.17 \pm 0.01$ & $101.2 \pm 0.03$ & $11.6 \pm 0.01$ \\
Group II & $1.35 \pm 0.03^{*}$ & $232.5 \pm 0.04^{\#}$ & $5.9 \pm 0.03^{\mathrm{a}}$ \\
Group III & $2.65 \pm 0.02^{* *}$ & $155.8 \pm 0.02^{\# \#}$ & $8.8 \pm 0.02^{\text {aa }}$ \\
Group IV & $3.01 \pm 0.01^{* * *}$ & $116.3 \pm 0.03^{\# \# \#}$ & $10.95 \pm 0.03^{\text {aaa }}$ \\
\hline
\end{tabular}

Values are expressed as mean $^{n} \pm$ S.D. for $n=3$. Data were analyzed by oneway ANOVA followed by the post hoc Tukey test. ${ }^{*} p<0.001$ as compared to group I, ${ }^{* *} p<0.01$ as compared to group II and ${ }^{* * *} p<0.001$ as compared to group II. $" p<0.001$ as compared to group I, ${ }^{\# \#} p<0.05$ as compared to group II and ${ }^{\# \#} p<0.01$ as compared to group II. ${ }^{a} p<0.001$ as compared to group I,

aa $p<0.05$ as compared to group II and aaa $p<0.001$ as compared to group II

\section{Conclusion}

The obtained results of the study clearly show the high antioxidant potential of the plant C. maritima and support its well-prescribed and extensive use in the treatment of cataract. The findings supports a protective role of C.maritima in pathologies involving oxidative stress, namely cataract. Our findings further corroborate the substantial presence of phenolic and flavonoid content signifying the plant to be a promising contender in treating cataract. However, further studies to identify and isolate the main constituents responsible for its anticataract effect from phenolic and flavonoid class to comprehend the proper dosage form for maximum benefits of this plant needs to be carried out in future.

\section{Abbreviations}

WHO: World health organization; CM: Cineraria maritima; UVNIS: Ultravioletvisible spectroscopy; w/v: Weight by volume; w/w: Weight by weight; $v /$ v: Volume by volume; DPPH: 1,1-Diphenyl-2-picrylhydrazyl; OS: Oxidative stress; ROS: Reactive oxygen species; TPC: Total phenolic content; TFC: Total flavonoid content; TPRC: Total protein content; GAE: Gallic acid equivalents; IU: International unit; MPI: Mean percentage inhibition

\section{Acknowledgements}

We are thankful to the Department of Pharmaceutical Sciences Sir JC Bose Technical Campus Bhimtal, Kumaun University Nainital, for giving the opportunity and facilities to conduct this research work. We would also like to extend our special thanks to Dr. Laxman Rautela for his kind support and help throughout the research work.

\section{Plant authentication and procurement}

The plant has been purchased from the Centre of Medicinal Plants Research in Homeopathy (Central Council for Research in Homeopathy), Nilgiri district, Tamil Nadu, India, in November 2019. The same has been identified and supplied as Senecio bicolor (Willd.) Tod, ssp. Cineraria synonyms: Cineraria bicolor Willd., Cineraria maritima L. belongs to the (Asteraceae). Certificate for the purchase and identification (F.No. 6-2/2019-20/CMPRH/Tech/212) of this plant has been issued by Dr. S. Rajan Officier Incharge Centre of Medicinal Plants Research in Homeopathy (Central Council for Research in Homeopathy) Emerald Tamil Nadu, India.

\section{Authors' contributions}

The entire theme and idea of the work was given by AV and VJ. Experimental studies were conducted and compiled by SD and further the overall results of the study were analyzed by both $\mathrm{AV}$ and VJ. Manuscript drafting was done by SD under the supervision of both professors. All authors have carefully read and approved the manuscript.

Funding

Not applicable

Availability of data and materials

All data and material are available upon request.

\section{Declarations}

Ethics approval and consent to participate

Not applicable

Consent for publication

Not applicable

Competing interests

No conflicts of interests to declare. 


\section{Author details}

'Department of Pharmaceutical Sciences Bhimtal, Kumaun University Nainital, Nainital, Uttarakhand Pin Code 263136, India. ${ }^{2}$ School of Pharmaceutical Sciences, IFTM University, Moradabad, Uttar Pradesh Pin Code 244102, India. ${ }^{3}$ Teerthankar Mahaveer College of Pharmacy, Teerthankar Mahaveer University, Moradabad, Uttar Pradesh Pin Code 244001, India.

Received: 27 January 2021 Accepted: 10 May 2021

Published online: 22 May 2021

\section{References}

1. Lee CM, Afshari NA (2017) The global state of cataract blindness. Curr Opin Ophthalmol 28(1):98-103

2. Hilliard A, Mendonca P, Russell TD, Soliman KF (2020) The protective effects of flavonoids in cataract formation through the activation of Nrf2 and the inhibition of MMP-9. Nutrients. 12(12):3651

3. Heruye SH, Maffofou Nkenyi LN, Singh NU, Yalzadeh D, Ngele KK, Njie-Mbye Y, Ohia SE, Opere CA (2020) Current trends in the pharmacotherapy of cataracts. Pharmaceuticals 13(1):1-41

4. Bourne RR (2021) Causes of blindness and vision impairment in 2020 and trends over 30 years, and prevalence of avoidable blindness in relation to VISION 2020: the right to sight: an analysis for the global burden of disease study. Lancet Glob Health 9(2):e144-e160

5. Astbury N, Nyamai LA (2016) Detecting and managing complications in cataract patients. Community Eye health 29(94):27-29

6. Karahan E, Er D, Kaynak S (2014) An overview of Nd: YAG laser capsulotomy. Med Hypothesis Discov Innov Ophthalmol 3(2):45-50

7. Radhakrishnan M, Venkatesh R, Valaguru V, Frick KD (2015) Economic and social factors that influence households not willing to undergo cataract surgery. Indian J Ophthalmol 63(7):594-599

8. Kaur J, Kukreja S, Kaur A, Malhotra N, Kaur R (2012) The oxidative stress in cataract patients. J Clin Diagn Res 6(10):1629-1632

9. Ho MC, Peng YJ, Chen SJ, Chiou SH (2010) Senile cataracts and oxidative stress. J Clin Gerontol Geriatr 1(1):17-21

10. Nita M, Grzybowski A (2016) The role of the reactive oxygen species and oxidative stress in the pathomechanism of the age-related ocular diseases and other pathologies of the anterior and posterior eye segments in adults. Oxidative Med Cell Longev 2016:1-23

11. Babizhayev MA (2016) Generation of reactive oxygen species in the anterior eye segment. Synergistic codrugs of N-acetylcarnosine lubricant eye drops and mitochondria-targeted antioxidant act as a powerful therapeutic platform for the treatment of cataracts and primary open-angle glaucoma. BBA Clin 6:49-68

12. Tewari D, Samoilă O, Gocan D, Mocan A, Moldovan C, Devkota HP, Atanasov AG, Zengin G, Echeverría J, Vodnar D, Szabo B, Crisan G (2019) Medicinal plants and natural products used in cataract management. Front Pharmacol 10:1-22

13. Srivastava NK, Bagchi GD (2006) Influence of micronutrient availability on biomass production in cineraria. Indian J Pharm Sci 68(2):238-239

14. Maggio A, Venditti A, Senatore F, Bruno M, Formisano C (2015) Chemical composition of the essential oil of Jacobaea maritima (L.) Pelser \& Meijden and Jacobaea maritima subsp. bicolor (Willd.) B. Nord. \& Greuter (Asteraceae) collected wild in Croatia and Sicily,respectively. Nat Prod Res 29(9):857-863

15. Burdon-Cooper J (1936) Cineraria maritima and the treatment of cataract. Br Med J 1(3914):85

16. Grace MH, Khattab AM (1998) Chemical constituents and molluscicidal activity of Senecio cineraria DC. Egypt J Pharm Sci 39(1/3):253-266

17. Tundis R, Loizzo MR, Statti GA, Passalacqua NG, Peruzzi L (2007) Menichini F. Pyrrolizidine alkaloid profiles of the Senecio cineraria group (Asteraceae). Z Naturforsch C 62(7-8):467-472

18. Anitha TS, Muralidharan AR, Annadurai T, Jesudasan CA, Thomas PA, Geraldine P (2013) Putative free radical-scavenging activity of an extract of Cineraria maritima in preventing selenite-induced cataractogenesis in Wistar rat pups. Mol Vis 19:2551-2560

19. Anitha TS, Annadurai T, Thomas PA, Geraldine P (2011) Prevention of selenite-induced cataractogenesis by an ethanolic extract of Cineraria maritima: an experimental evaluation of the traditional eye medication. Biol Trace Elem Res 143(1):425-436

20. Maria R, Shirley M, Xavier C, Jaime S, David V, Rosa S, Jodie D (2018) Preliminary phytochemical screening, total phenolic content and antibacterial activity of thirteen native species from Guayas province Ecuador. J King Saud Univ Sci 30(4):500-505

21. Gul R, Jan SU, Faridullah S, Sherani S, Jahan N (2017) Preliminary phytochemical screening, quantitative analysis of alkaloids, and antioxidant activity of crude plant extracts from Ephedra intermedia indigenous to Balochistan. The Sci World J 2017:1-7

22. Shukla S, Mehta A, Bajpai VK (2013) Phytochemical screening and anthelmintic and antifungal activities of leaf extracts of Stevia rebaudiana. JBAPN 3(1):56-63

23. Iqbal E, Salim KA, Lim LB (2015) Phytochemical screening, total phenolics and antioxidant activities of bark and leaf extracts of Goniothalamus velutinus (airy Shaw) from Brunei Darussalam. J King Saud Univ Sci 27(3): 224-232

24. Njoya EM, Munvera AM, Mkounga P, Nkengfack AE, McGaw LJ (2017) Phytochemical analysis with free radical scavenging, nitric oxide inhibition and antiproliferative activity of Sarcocephalus pobeguinii extracts. BMC Compl Alternative Med 17(1):199

25. Madaan R, Bansal G, Kumar S, Sharma A (2011) Estimation of total phenols and flavonoids in extracts of Actaea spicata roots and antioxidant activity studies. Indian J Pharm Sci 73(6):666-669

26. Alam MN, Bristi NJ, Rafiquzzaman M (2013) Review on in vivo and in vitro methods evaluation of antioxidant activity. Saudi Pharm J 21(2):143-152

27. Karagöz A, Artun FT, Özcan G, Melikoğlu G, Anıl S, Kültür S, Sütlüpınar N (2015) In vitro evaluation of antioxidant activity of some plant methano extracts. Biotechnol Biotechnol Equip 29(6):21184-21189

28. Park CH, Yeo HJ, Baskar TB, Park YE, Park JS, Lee SK, Park SU (2019) In vitro antioxidant and antimicrobial properties of flower, leaf, and stem extracts of Korean mint. Antioxidants 8(3):75

29. Priyanka B, Anitha K, Shirisha K, Janipasha SK, Dipankar B et al (2013) Evaluation of antioxidant activity of ethanolic root extract of Albizia lebbeck (L) Benth. Int Res J Pharm Appl Sci 3:93-101

30. Mazhangara IR, Idamokoro EM, Chivandi E, Afolayan AJ (2020) Phytochemical screening and in vitro evaluation of antioxidant and antibacterial activities of Teucrium trifidum crude extracts. Heliyon 6(9): e04395

31. Pavithra K, Vadivukkarasi S (2015) Evaluation of free radical scavenging activity of various extracts of leaves from Kedrostis foetidissima (Jacq.) Cogn. Food Sci Human Wellness 4(1):42-46

32. Mahdi-Pour B, Jothy SL, Latha LY, Chen Y, Sasidharan S (2012) Antioxidant activity of methanol extracts of different parts of Lantana camara. Asian Pac J Trop Biomed 2(12):960-965

33. Gupta SK, Kalaiselvan V, Srivastava S, Agrawal SS, Saxena R (2010) Evaluation of anticataract potential of Triphala in selenite-induced cataract: in vitro and in vivo studies. J Ayurveda Integr Med 1(4):280-286

34. Hajarnavis AM, Bulakh PM (2020) Anticataract effects of S. cumini and A. marmelos on goat lenses in an experimental diabetic cataract model. J Ayurveda Integr Med 11:421-425

35. Patra JK, Das G, Fraceto LF, Campos EV, del Pilar R-TM, Acosta-Torres LS, Diaz-Torres LA, Grillo R, Swamy MK, Sharma S, Habtemariam S (2018) Nano based drug delivery systems: recent developments and future prospects. J Nanobiotechnol 16(1):1-33

36. Salehi B, Azzini E, Zucca P, Maria Varoni E, V Anil Kumar N, Dini L, Panzarini E, Rajkovic J, Valere Tsouh Fokou P, Peluso I, Prakash Mishra A (2020) Plantderived bioactives and oxidative stress-related disorders: a key trend towards healthy aging and longevity promotion. Appl Sci 10(3):947

37. Lin S, Ge C, Wang D, Xie Q, Wu B, Wang J, Nan K, Zheng Q, Chen W (2019) Overcoming the anatomical and physiological barriers in topical eye surface medication using a peptide-decorated polymeric micelle. ACS Appl Mater Interfaces 11(43):39603-39612

\section{Publisher's Note}

Springer Nature remains neutral with regard to jurisdictional claims in published maps and institutional affiliations. 